\title{
Freedom is a state of mind
}

\author{
by Loco
}

P.I. Neuwegein

\begin{abstract}
Artwork by Loco, an incarcerated artist at P.I. Neuwegein, The Netherlands.
\end{abstract}
Key words: Prison education; art education

In this piece of prison art Loco touches one of the most revered subjects: the juxtaposition of freedom and individuality in the most extreme environments. Turning one notch up his impressive nib pen technique his drawing excels in conveying the message of inner and outer freedom, in the unique way that can only be expressed from a situation of inner and outer seclusion. The overall picture synthesizes his experience in comic book illustration and his interest in formal $20^{\text {Th }}$ century revisionism and pop art. He drinks from the fountains of Crumb, Esher, Lloyd, Haring and Lichenstein, but with an added darkness that reminisces more of a tortured Scarfe. His cinema cues are also obvious: his revered idols Burton, Sayadian and Murnau come out of the woodwork in the intriguing contrasts and shadow treatments.

On a more detailed viewing hidden clues and places, some too familiar to other prisoners, some genuinely individual, appear on the forefront. The bullet, the anarchy as an irreverent pose, the night monster turned guard, the gang tattoo, the woman are all there to complement the idea that there is a parallel between the inner and outer liberties ever so evident when you are detained.

Pete Sinfield once said: "We all live in a prison, but some of us are lucky, our prison cell has windows". Loco proves to us once again that we are closer to this than what we might think.

--R.C.S. 


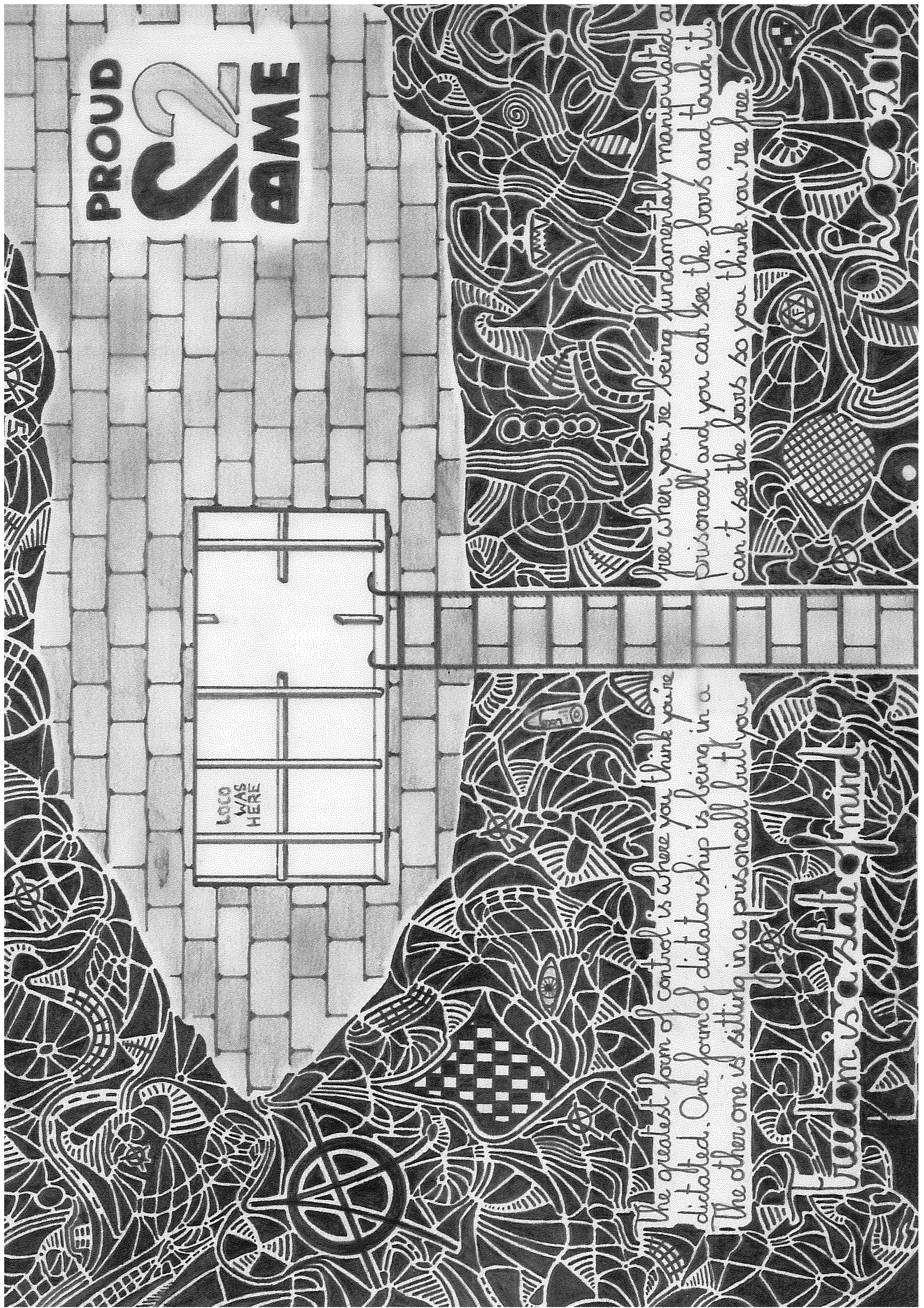

